\section{In vitro and In vivo Effects of Aloe ferox Extracts on Gas- trointestinal Nematodes Con- trol and Live Weight Gain of Young Sheep}

\author{
Ahmed $\mathbf{M}^{1 *}$, Basha $\mathrm{NA}^{1,3}$, Laing $\mathrm{MD}^{2}$ and Nsahlai IV \\ ${ }^{1}$ Department of Animal \& Poultry Science, University of KwaZulu-Natal, \\ Durban, South Africa \\ ${ }^{2}$ Discipline of Plant Pathology, University of KwaZulu-Natal, Durban, South \\ Africa
}

${ }^{3}$ Department of Animal Nutrition, Faculty of Animal Production, University of Khartoum, Khartoum, Sudan

\begin{abstract}
Gastrointestinal nematodes reduce production of small ruminants globally. Producing cheap and safe anthelmintic drugs with novel modes of action is the aspiration of many involved in this field. This study evaluated the in vitro and in vivo effects of a medicinal plant, Aloe ferox Mill, on gastrointestinal nematodes in sheep. Ethanolic extracts of different $A$. ferox fractions (dried leaves, pulp and cuticle, and gel of fresh leaves) were tested in vitro after dilution with water to concentrations of 5,10 and $20 \%$ of the concentrate. Dried leaves had the greatest effect $(P<0.001)$ on nematode larvae. A further in vivo investigation was done using twenty four lambs, aged 3-4 months (initial body weights of $22.1 \pm 4.3 \mathrm{~kg}$ ) were used. Gender, initial Eggs Per Gram (EPG) of faeces and initial body weight were used to place lambs into four groups of 6 lambs. Groups were then assigned to 4 treatments randomly. Dried, powdered leaves of $A$. ferox at $0,50 \mathrm{~g}, 100 \mathrm{~g}$ and $250 \mathrm{~g}$ per lamb were given daily for 10 weeks after it was mixed with a standard feed. Lambs were weighed weekly. Rectal faecal samples were taken every 7 days up to Day 70 , and EPG were counted in individual samples. Average Daily Gain (ADG) increased with $A$. ferox treatments, whereas EPG decreased $(P<0.001)$ with time. Feeding of $250 \mathrm{~g}$ of dried, powdered $A$. ferox leaves resulted in the highest ADG and maximum reduction of EPG. These findings suggest that $A$. ferox has the potential to improve animal weight gain and to suppress the production of eggs by gastrointestinal nematodes.
\end{abstract}

*Corresponding author: Ahmed M, Department of Animal \& Poultry Science, University of KwaZulu-Natal, Durban, South Africa, Tel: +273 32605474; E-mail: Ahmedm@ukzn.ac.za

Citation: Ahmed M, Basha NA, Laing MD, Nsahlai IV (2017) In vitro and In vivo Effects of Aloe ferox Extracts on Gastrointestinal Nematodes Control and Live Weight Gain of Young Sheep. J Anim Res Vet Sci 1: 003.

Received: September 26, 2017; Accepted: November 09, 2017; Published: November 22, 2017

Copyright: () 2017 Ahmed M, et al. This is an open-access article distributed under the terms of the Creative Commons Attribution License, which permits unrestricted use, distribution, and reproduction in any medium, provided the original author and source are credited.
Keywords: Aloe ferox; Biological control; Ethanolic plant extracts; Nematodes; Sheep

\section{Introduction}

Gastrointestinal Nematode (GIN) infections are a serious veterinary health challenge and the existing means are in adequate for addressing the problem [1]. In general, GINs reduce productivity of small ruminants by means of lowering fertility, reducing in milk production and depressing weight gain when feed intake is reduced [2].

In addition, loss of endogenous protein, anemia and impact on animal health. Treatment costs are high. In critical situations, death may result from severe infections [3]. Currently, the conventional control strategy for GIN infections is the use of synthetic anthelmintic drugs [4]. However, development of resistance by the parasites to the available drugs is widespread, and alternative control measures are needed. Consumers of animal by-products have also become cautious of possible contamination of meat and milk products as a result of drug residues. Small-scale farmers are leaving the livestock industry because of the unaffordable cost of drugs. Thus, alternative methods for controlling GINs are being studied. These include supplementing feed with medicinal plant products with anthelmintic properties.

The effect of supplementing animal feed with anthelmintic plant products depends upon the availability of that plant, its palatability and selective behaviour of animals. However, many plants have shown potential to control GINs in animals, such as Sericea lespedeza Dum. Cours. [5], Ficus spp. [6] and Aloe ferox Mill [7]. Their anthelmintic properties are attached to various active ingredients and their concentrations in the plants. However, some of these active ingredients have been associated with adverse reactions when fed to livestock. For example, tannins, the recognised active substance in Sericea lespedeza and Acacia spp., when fed to livestock in large quantities, reduce voluntary feed intake and digestibility [5].

The objectives of the current study were to determine the in $v i$ tro effects of variousfractions of $A$. ferox plants on nematodes larvae. Further, to examine in vivo their anthelmintic activity and their effect on body weight gain of lambs when fed A. Ferox plant in feed.

\section{Material and Methods}

\section{Plant collection and preparation}

Aloe ferox plant material was collected from a private garden in Pietermaritzburg. A voucher specimen of plant was deposited at the UKZN Herbarium, Pietermaritzburg. Ethanolic extracts of three plant fractions (dried leaves, skins of fresh leaves and the gel of fresh leaves) were prepared as per [8]. Ten gram samples of the dried leaves and skin of fresh leaves and $10 \mathrm{ml}$ of the gel of fresh leaves were boiled for 24 hours in $100 \mathrm{ml}$ of ethanol in a Soxhlet's apparatus. The resulting extracts were transferred to $50 \mathrm{ml}$ test tubes and placed in a waterbath (LABOTEC, Model 101, South Africa) at $50^{\circ} \mathrm{C}$. Extracts were condensed by evaporation of the solvent to a final volume of $30 \mathrm{ml}$. Condensed extracts were then preserved in airtight glass bottles and stored at $10^{\circ} \mathrm{C}$ until required for screening.

\section{In vitro anti-nematodal activity of Aloe ferox products}

Faecal samples were collected from 24 randomly selected Merino sheep grazing on a contaminated kikuyu pasture (Pennisetum 
clandestinum Hochst. ex Chiov.) at ukulinga research farm. Rectal faecal samples were taken from sheep by hand and stored in plastic bags. Faeces were pooled and mixed. Sub-samples $(5 \mathrm{~g})$ were placed in trays and incubated for 12 days at $27^{\circ} \mathrm{C}$. Samples were kept damp by daily watering at $09: 00 \mathrm{~h}$ during the period of incubation. On day 10 , ethanol extracts of the three plant fractions (dried leaves, skins of fresh leaves and the gel of fresh leaves) were applied in 5, 10 and $20 \%$ concentration ( $\mathrm{v} / \mathrm{v}$ water). Each treatment was used to treat 4 trays and there were 4 controls where only an ethanol/water solution at $20 \%$ was used. Both control and treated trays were incubated for a further 48 hrs. Baermann Technique was used to count nematode larvae as described by [9]. Samples were examined and larvae were counted using 100x magnification, after adding $0.2 \mathrm{ml}$ of iodine stain to the slide and covered with a cover-slip.

\section{In vivo screening of different dosages of $A$. ferox leaves}

In a second experiment, dry powdered leaves of $A$. ferox were testedin an in vivo trail due to great efficacy in experiment (1). Twenty four lambs (12 females and 12 males), aged 3-4 months, with initial body weights of $22.1 \pm 4.3 \mathrm{~kg}$, were used. The initial faecal egg counts were determined in rectal faecal samples. Gender, initial Eggs Per Gram (EPG) of faeces and initial body weight were used to place the sheep into four groups of six lambs each and then each group was randomly assigned to a treatment. Sheep were naturally infected with mixed cultures of gastrointestinal nematodes. Haemonchuscontortus (Rudolphi, 1803) at 27\% predominant species, others like Trichostrongylus, Strongyloides, Coopera and Nematodirus Spp were also found [4]. Sheep were housed in pens $(0.90 * 1.50 \mathrm{~m})$ in sheep facility at ukulinga research farm. Each pen was provided with an individual feeder and drinker on wooden slatted flooring. The facility was temperature regulated with large fans.

Four level of dry powdered leaves of $A$. ferox $(0,50 \mathrm{~g}, 100 \mathrm{~g}$ and $250 \mathrm{~g}$ ) were added to standard lambs feed which consisted of the following ingredients: Cottonseed cake (37.5kg), hominy chop (33.3kg), molasses liquid $(8.6 \mathrm{~kg})$ and Vit. Premix $(1.1 \mathrm{~kg})$. Lambs were fed the standard diet daily between 07: 00-09: 00h and then given veld hayand water ad libitum.

During a 14-days pre-treatment period, sheep were randomly allocated to individual sheep feeding stalls to acclimatize them to handling facilities. At the end of this period, faecal samples were collected and nematode Eggs Per Gram of feaces (EPG) were determined. During this trial, sheep were assigned to one of four treatments: Standard feed without treatment (control), and $50 \mathrm{~g}, 100 \mathrm{~g}$ and $250 \mathrm{~g}$ of dry powdered A. ferox leaves per sheep daily. Treatments were mixed with the feed formulation given daily for 10 weeks.

Lambs were weighted every week up to Day 70. Rectal grab samples were collected weekly during the experiment for nematode egg counts using the McMaster Technique, according to [9].

\section{Statistical Analysis}

Nematode mortality from faecal cultures was calculated using Abbott's Formula [10], as follows:

$$
\text { Corrected } \%=\left(1-\frac{n \text { in } T \text { after treatment }}{n \text { in Co after treatment }}\right) \times 100
$$

Where;

$\mathrm{n}=$ number of larvae; $\mathrm{T}=$ Treated; $\mathrm{Co}=\mathrm{Control}$

Nematode larvae counts were analysed using the General Linear Model procedure of SAS (2000). In trial 1, the following statistical model was used to analyse larval mortality at specific concentrations:

$$
\mathrm{Y}_{\mathrm{ij}}=\mu+\mathrm{S}_{\mathrm{i}}+\mathrm{e}_{\mathrm{ij}} \text {; }
$$

Where, $Y_{i j}=$ individual observation; $\mu=$ overall mean; $S_{i}=$ effect of plant parts; $\mathrm{e}_{\mathrm{ij}}=$ the error term.

Data on faecal egg counts wereanalyzed by using the General Linear Model (GLM) procedure of SAS (2000), according to the following model:

$$
\mathrm{Y}_{\mathrm{ijk} l}=\mu+\mathrm{W}_{\mathrm{i}}+\mathrm{T}_{\mathrm{j}}+\left(\mathrm{W}^{*} \mathrm{~T}\right)_{\mathrm{ij}}+\mathrm{G}_{\mathrm{k}}+\mathrm{L}_{1}+\mathrm{e}_{\mathrm{ijkl}}
$$

where: $Y_{\mathrm{ijk}}=$ individual daily observation; $\mu=$ overall mean; $\mathrm{W}_{\mathrm{i}}=$ weekly effect; $\mathrm{T}_{\mathrm{j}}=$ effect of treatment; $\left(\mathrm{W}^{*} \mathrm{~T}\right)_{\mathrm{ij}}=$ interaction between week and treatment; $\mathrm{G}_{\mathrm{k}}=$ co-variate effect of initial egg count, $\mathrm{L}_{1}=$ co-variate effect of initial body weight and $\mathrm{e}_{\mathrm{ijkl}}=$ the error term.

Log transformations were applied to EPG to normalize variance. These data were presented in Table 3 together with the untransformed means, which are easier to interpret. The transformed data were analyzed using the same statistical model.

\section{Results}

\section{In vitro screening of Aloe ferox extracts for anthelmintic activity}

Ethanol extracts from different fractions of A.ferox plant had varied $(\mathrm{P}<0.001)$ effects on nematode larvae from sheep at the three concentrations $(5,10$ and $20 \%)$ (Table1). Increasing of the concentration caused stronger larvicidal effects. Dry powdered leaves extract at various concentrations $(5,10$ and $20 \%$ ) had the lowest larvaecounts (75.7-86.9\%), followed by skin of fresh leaves (68.3-75.4\%), and the

\begin{tabular}{|c|c|c|c|}
\hline \multirow[t]{2}{*}{ Aloe Ferox Parts Used } & \multicolumn{2}{|c|}{ Ethanolic Extract C } & $\begin{array}{l}\text { Concentrations\% } \quad(\mathrm{v} / \mathrm{v} \text { with } \\
\text { water) }\end{array}$ \\
\hline & 5 & 10 & 20 \\
\hline Dried powdered leaves & $75.7 \pm 4.2$ & $84.2 \pm 3.7$ & $86.9 \pm 2.9$ \\
\hline Gel from leaves & $48.7 \pm 2.7$ & $58.3 \pm 2.7$ & $61.4 \pm 3.3$ \\
\hline Skin of fresh leaves & $68.3 \pm 3.4$ & $72.9 \pm 2.1$ & $75.4 \pm 1.0$ \\
\hline Control & $30.5 \pm 2.1$ & $33.5 \pm 3.4$ & $39.3 \pm 2.1$ \\
\hline F value & 5.74 & 4.67 & 4.23 \\
\hline $\mathrm{CV} \%$ & 12.55 & 10.43 & 11.67 \\
\hline $\mathbf{P}<$ & 0.001 & 0.001 & 0.001 \\
\hline
\end{tabular}
gel from fresh leaves (48.7-61.4\%). The control had the highest larvae counts (30.5-39.3\%) (Table 1).

Table 1: In vitro efficacy of ethanol extracts of different fractions of a medicinal plant (Aloe ferox) against a mixed culture of gastrointestinal nematode larvae of sheep. $\mathrm{CV} \%=$ Coefficient of Variance

\section{Live-weight gain}

The aloe treatments had significant effects on the live weight of lambs by day 70 (Table 2). All treatments resulted in increased sheep live weight. However, sheep given $250 \mathrm{~g}$ of A.ferox treatment had the greatest average daily gain of $57.74 \mathrm{~g}$, while the Control treatment had the least average daily gain of $14.88 \mathrm{~g}$. 


\begin{tabular}{|c|c|c|c|c|}
\hline Treatments & Wt0 (kg) & Wt70 (kg) & ADG (g) & Rank \\
\hline $50 \mathrm{~g}$ & 25.96 & 29.92 & 56.55 & 3 \\
\hline $100 \mathrm{~g}$ & 26.04 & 29.71 & 52.38 & 2 \\
\hline $250 \mathrm{~g}$ & 25.71 & 29.75 & 57.74 & 1 \\
\hline Control & 25.58 & 26.63 & 14.88 & 4 \\
\hline F value & & 1.67 & 15.19 & \\
\hline P & & 0.1874 & 0.001 & \\
\hline LSD & & NA & 3.51 & \\
\hline CV\% & & 14.66 & 13.08 & \\
\hline \multicolumn{7}{|c|}{ Table 2: Effect of treatments on sheep weight. } \\
\hline
\end{tabular}

$\mathrm{W}_{0}=$ weight on Day $0, \mathrm{~W}_{70}=$ weight on Day $70, \mathrm{ADG}=$ Average Daily Gain; $\mathrm{LSD}=$ Least Significant Difference; $\mathrm{CV} \%=$ Coefficient of Variance.

\section{Effect of Aloe ferox plant extracts on nematode eggs count}

The nematode egg counts varied $(\mathrm{P}<0.001)$ with treatment (Table 3). Pre-treatment EPG counts averaged 1633, 1683, 1758 and 1667 for the Control and sheep fed daily with 50,100 and 250g of A.ferox /sheep, respectively. However, by week 10, the EPG counts averaged $1542,900,833$ and 492 for the four treatments, respectively.

\section{Discussion}

Ethanolic extracts of all fractions of $A$. ferox used in this study showed larvicidal effects against nematodes larvae in vitro. However, dry powdered leaves extracts provided the best larval inhibition at all concentrations. This finding confirms similar work in which an ethanolic extract of $A$. ferox had been used to control $H$. contortus of sheep [7-8] reported in vitro larvicidal effects of aqueous extracts of A. ferox leaves on $H$. contortus from goats. Gel from A. ferox leaves exhibited weak anthelminthic activity compared to other fractions. [11] reported that the gel of $A$. ferox leaves has less secondary compounds with biological activity, as these are found in the sap and outer leaf, and not in the inner gel of the aloe plant. This would explain the efficacy of theskin of fresh leaves. The gel was removed before extracting the rest of the Aloe leaves, thus different results were obtained especially since the polysaccharine gel components would be more water soluble than the rest of the aloe leaves [7]. However, the active compounds are yet to be clearly identified.

In vivo data showed a reduction in the Faecal Egg Counts (FEC) resulting all doses fromaloe treatment compared with the control group, indicating strong anthelminthic activity. Study on goats using A. Ferox extracts have reported reductions $(\mathrm{P}<0.05)$ in strongyle eggs, administration of two doses of 250 and $500 \mathrm{mgkg}^{-1}$ at a concentration of $100 \mathrm{mgml}^{-1}$ per animal for 9 days decreased faecal egg count dramatically $[12,13]$ also found a significant $(\mathrm{P}<0.001)$ decrease of nematode egg counts in naturally infected sheep treated with an $A$. ferox extract. Weekly dosing of $100 \mathrm{mg}$ of $A$. ferox $\mathrm{kg}^{-1}$ body weight per sheep for 42 days reduced egg counts and numbers of larvae recovered from faecal cultures. [14] found A. ferox has a negative effect on nematodes due to the glucoside aloin content, which may cause expulsion of worms from the gastrointestinal tract. Aloe ferox extract could affect the egg laying ability of the female adult worms, resulting in reducing of FEC [12]. However, the in vitro trial here showed the aloe extract was directly nematicidal.

In this study, there was an increased in live weight gain of treated animals. This confirmed the study of [13], where sheep weight increased when the animals were dosed with an A. ferox extract. [15] reported that the means of live weight of lambs treated with Khayasenegalensis Desr. extract also improved.

\section{Conclusion}

Aloeferox plant possesses anthelminthic properties against nematode parasites of sheep in vitro and in vivo. Consumption of Aloe ferox also resulting in apositive effect on body weight gain. Supplementing sheep feed with powdered A. Ferox leaves is a viable treatment to enhance weight gain and control of GI nematodes.

\section{Acknowledgement}

The authors are grateful for research funding that was provided by the National Research Foundation, South Africa.

\begin{tabular}{|c|c|c|c|c|c|c|c|c|c|c|c|}
\hline \multirow{2}{*}{$\begin{array}{c}\text { Treatment } \\
\text { (g of } \text { A.ferox } / \text { sheep) }\end{array}$} & \multicolumn{11}{|c|}{ Mean Values of Eggs Per Gram of Faeces } \\
\hline & Week 0 & Week 1 & Week 2 & Week 3 & Week 4 & Week 5 & Week 6 & Week 7 & Week 8 & Week 9 & Week 10 \\
\hline 50 & $1683 \pm 414$ & $1692 \pm 459$ & $1642 \pm 486$ & $1617 \pm 470$ & $1508 \pm 457$ & $1233 \pm 459$ & $1158 \pm 440$ & $1117 \pm 430$ & $1067 \pm 433$ & $983 \pm 415$ & $900 \pm 404$ \\
\hline 100 & $1758 \pm 257$ & $1750 \pm 251$ & $1700 \pm 243$ & $1550 \pm 225$ & $1450 \pm 268$ & $1058 \pm 281$ & $1017 \pm 248$ & $1000 \pm 227$ & $983 \pm 199$ & $867 \pm 210$ & $833 \pm 183$ \\
\hline 250 & $1667 \pm 311$ & $1675 \pm 316$ & $1550 \pm 317$ & $1350 \pm 304$ & $1242 \pm 294$ & $983 \pm 287$ & $958 \pm 286$ & $900 \pm 283$ & $792 \pm 295$ & $700 \pm 282$ & $592 \pm 214$ \\
\hline 0 & $1633 \pm 447$ & $1667 \pm 442$ & $1700 \pm 435$ & $1758 \pm 432$ & $1758 \pm 408$ & $1758 \pm 407$ & $1608 \pm 403$ & $1558 \pm 411$ & $1550 \pm 415$ & $1550 \pm 422$ & $1542 \pm 437$ \\
\hline F value & 0.01 & 0.01 & 0.03 & 0.15 & 0.25 & 0.95 & 1.12 & 1.15 & 1.47 & 2.23 & 3.52 \\
\hline $\mathrm{CV} \%$ & 67.94 & 64.43 & 66.13 & 67.73 & 70.36 & 69.69 & 57.45 & 58.01 & 59.44 & 59.01 & 60.74 \\
\hline $\mathrm{P}<$ & 0.998 & 0.999 & 0.994 & 0.926 & 0.863 & 0.434 & 0.364 & 0.354 & 0.253 & 0.001 & 0.001 \\
\hline Treatment & \multicolumn{11}{|c|}{ Transformed egg per gram of faeces (Log transformed) } \\
\hline (g of A.ferox/sheep) & Week 0 & Week 1 & Week 2 & Week 3 & Week 4 & Week 5 & Week 6 & Week 7 & Week 8 & Week 9 & Week 10 \\
\hline 50 & $3.13 \pm 0.05$ & $3.13 \pm 0.06$ & $3.12 \pm 0.06$ & $3.11 \pm 0.06$ & $3.09 \pm 0.06$ & $3.03 \pm 0.06$ & $3.01 \pm 0.06$ & $2.99 \pm 0.06$ & $2.98 \pm 0.06$ & $2.95 \pm 0.06$ & $2.92 \pm 0.06$ \\
\hline 100 & $3.19 \pm 0.04$ & $3.18 \pm 0.04$ & $3.17 \pm 0.04$ & $3.14 \pm 0.04$ & $3.11 \pm 0.05$ & $2.98 \pm 0.06$ & $2.97 \pm 0.05$ & $2.95 \pm 0.05$ & $2.93 \pm 0.04$ & $2.88 \pm 0.05$ & $2.85 \pm 0.04$ \\
\hline 250 & $3.18 \pm 0.04$ & $3.19 \pm 0.04$ & $3.15 \pm 0.04$ & $3.09 \pm 0.04$ & $3.04 \pm 0.04$ & $2.96 \pm 0.04$ & $2.95 \pm 0.04$ & $2.93 \pm 0.04$ & $2.87 \pm 0.05$ & $2.83 \pm 0.04$ & $2.68 \pm 0.04$ \\
\hline 0 & $3.17 \pm 0.06$ & $3.13 \pm 0.06$ & $3.14 \pm 0.06$ & $3.15 \pm 0.06$ & $3.15 \pm 0.06$ & $3.15 \pm 0.06$ & $3.14 \pm 0.07$ & $3.13 \pm 0.07$ & $3.13 \pm 0.07$ & $3.13 \pm 0.07$ & $3.13 \pm 0.08$ \\
\hline F value & 0.11 & 0.1 & 0.04 & 0.08 & 0.21 & 0.84 & 0.96 & 0.98 & 1.41 & 2.34 & 4.79 \\
\hline $\mathrm{CV} \%$ & 8.34 & 8.31 & 8.27 & 8.27 & 8.58 & 7.47 & 6.95 & 7.19 & 7.37 & 7.05 & 7.23 \\
\hline $\mathbf{P}<$ & 0.953 & 0.961 & 0.988 & 0.968 & 0.888 & 0.487 & 0.43 & 0.4238 & 0.27 & 0.001 & 0.001 \\
\hline
\end{tabular}

Table 3: Effect of different concentrations of Aloe ferox plants on the mean number of nematode eggs per gram of faeces in lambs. 


\section{References}

1. Van Wyk JA, Stenson MO, Van der Merwe JS, Vorster RJ, Viljoen PG (1999) Anthelmintic resistance in South Africa: surveys indicate an extremely serious situation in sheep and goat farming. Onderstepoort J Vet Res 66: 273-284.

2. Azrul LM, Nurulaini R, Adzemi MA, Marina H, Effendy AWM (2014) Tannins Quantification in Terminalia catappa Leaves Extract and Antihelmenthic Potential Evaluation. Journal of Natural Products 7: 98-103.

3. Fikru R, Sori T, Dhuguma R, Kiros Y (2006) Epidemiology of gastrointestinal parasites of ruminants in Western Oromia, Ethiopia. International Journal Applied Research for Veterinary Medicine 4: 51-57.

4. Ahmed M (2010) 'Gastrointestinal (nematode) infections in small ruminants: Epidemiology, anthelmintic efficacy and the effect of wattle tannins'. Animal Science, Pietermaritzburg, South Africa.

5. Min BR, Hart SP, Miller D, Tomita GM, Loetz E, et al. (2005) The effect of grazing forage containing condensed tannins on gastro-intestinal parasite infection and milk composition in Angora does. Vet Parasitol 130: $105-113$.

6. Gillian S, Behnke JM, Buttle DJ, Duce LR (2004) Natural plant cysteine proteinases as anthelmintics? Trends in Parasitology 20: 322-327.

7. Maphosa V, Masika PJ, Bizimenyera ES, Eloff JN (2010) In-vitro anthelminthic activity of crude aqueous extracts of Aloe ferox, Leonotis leonurus and Elephantorrhiza elephantina against Haemonchus contortus. Trop Anim Health Prod 42: 301-307.

8. Ahmed M, Nsahlai I, Laing M (2012) In vitro anthelmintic activity of crude extracts of selected medicinal plants against Haemonchus contortus from sheep. J Helminthol 87: 174-179.
9. Hansen J, Perry B (1994) The Epidemiology, Diagnosis and Control of Helminth Parasites of Ruminants. International Laboratory for Research on Animal Diseases Press, Nairobi, Kenya.

10. Abbott WS (1925) A method of computing the effectiveness of an insecticide. Journal of Economic Entomology 18: 265-267.

11. Eshun K, He Q (2004) Aloe vera: a valuable ingredient for the food, pharmaceutical and cosmetic industries- a review. Crit Rev Food Sci Nutr 44: 91-96.

12. Maphosa V, Masika PJ (2012) In vivo validation of Aloe ferox (Mill). Elephantorrhiza elephantina Bruch. Skeels. and Leonotisleonurus (L) R. BRas BRas potential anthelminthics and antiprotozoals against mixedinfections of gastrointestinal nematodes in goats. Parasitol Res 110: 103-108.

13. Ahmed M, Laing MD, Nsahlai IV (2014) In vivo effect of selected medicinal plants against gastrointestinal nematodes of sheep. Trop Anim Health Prod 46: 411-417.

14. Wyk BE, Van Ousdtshoorn B, Gericke N (2002) Medicinal Plants of South Africa. Briza Publication, Pretoria, South Africa.

15. Ademola IO, Fagbemi BO, Idowu SO (2004) Evaluation of the anthelmintic activity of Khayasenegalensis extract against gastrointestinal nematodes of sheep: In vitro and in vivo studies. Veterinary Parasitology 122: 151-164. 